\title{
The Anticonvulsants Lamotrigine, Riluzole, and Valproate Differentially Regulate AMPA Receptor Membrane Localization: Relationship to Clinical Effects in Mood Disorders
}

\author{
Jing Du', Katsuji Suzuki', Yanling Wei', Yun Wang', Rayah Blumenthal', Zheng Chen', Cynthia Falke', \\ Carlos A Zarate Jr' and Husseini K Manji*,' \\ 'Laboratory of Molecular Pathophysiology, Mood and Anxiety Disorders Program, National Institute of Mental Health, National Institutes \\ of Health, Bethesda, MD, USA
}

\begin{abstract}
A growing body of data suggests that the glutamatergic system may be involved in the pathophysiology and treatment of severe mood disorders. Chronic treatment with the antimanic agents, lithium and valproate, resulted in reduced synaptic expression of the AMPA(-amino-3-hydroxy-5-methylisoxazole-4-propionic acid) receptor subunit GluRI in the hippocampus, while treatment with an antidepressant (imipramine) enhanced the synaptic expression of GluRI. The anticonvulsants, lamotrigine (6-(2,3-dichlorophenyl)- I,2,4triazine-3,5-diamine) and riluzole (2-amino-6-trifluoromethoxybenzothiazole), have been demonstrated to have efficacy in the depressive phase of bipolar disorder. We therefore sought to determine the role of these anticonvulsants, compared to that of the predominantly antimanic anticonvulsant valproate, on AMPA receptor localization. We found that the agents with a predominantly antidepressant profile, namely lamotrigine and riluzole, significantly enhanced the surface expression of GluRI and GluR2 in a time- and dose-dependent manner in cultured hippocampal neurons. By contrast, the predominantly antimanic agent, valproate, significantly reduced surface expression of GluRI and GluR2. Concomitant with the GluRI and GluR2 changes, the peak value of depolarized membrane potential evoked by AMPA was significantly higher in lamotrigine- and riluzole-treated neurons, supporting the surface receptor changes. Phosphorylation of GluRI at the PKA (cAMP-dependent protein kinase) site (S845) was enhanced in both lamotrigine- and riluzoletreated hippocampal neurons, but reduced in valproate-treated neurons. In addition, lamotrigine and riluzole, as well as the traditional antidepressant imipramine, also increased GluRI phosphorylation at GluRI (S845) in the hippocampus after chronic in vivo treatment. Our findings suggest that regulation of GluRI/2 surface levels and function may be responsible for the different clinical profile of anticonvulsants (antimanic or antidepressant), and may suggest avenues for the development of novel therapeutics for these illnesses. Neuropsychopharmacology (2007) 32, 793-802. doi: I0.1038/sj.npp. I30 I I78; published online 16 August 2006
\end{abstract}

Keywords: AMPA receptors; phosphorylation; lamotrigine; riluzole; valproate; imipramine

\section{INTRODUCTION}

Bipolar disorder is a common, severe, and often lifethreatening disorder. The recognition of the significant morbidity and mortality of patients with severe mood disorders, as well as the growing appreciation that a significant percentage of patients respond poorly to existing treatments has made the task of discovering new therapeutic agents increasingly more important. In recent years, a

*Correspondence: Dr HK Manji, Laboratory of Molecular Pathophysiology, Mood and Anxiety Disorders Program, National Institute of Mental Health, 9000 Rockville Pike, Building 35, I C9I2, Bethesda, MD 20892, USA, Tel: + I 30| 45। 844I, Fax: + I 30| 480 0I23,

E-mail: manjih@mail.nih.gov

Received 17 October 2005; revised 30 June 2006; accepted 3 July 2006 Online publication: 12 July 2006 at http:/www.acnp.org/citations/ Npp07| 206050630/default.pdf growing number of anticonvulsants have been utilized in the treatment of the disorder (Ernst and Goldberg, 2003; Evins, 2003). Indeed, based on the ability of anticonvulsants to reduce neural excitability, there has been a growing assumption that most anticonvulsants would have some utility in the treatment of the manic phase of the disorder; such a contention is supported by the widespread use of valproate for the treatment of the manic phase of the disorder. This assumption was called into question by the demonstration - in a double-blind, placebo-controlled study - that lamotrigine (6-(2,3-dichlorophenyl)-1,2,4-triazine-3,5-diamine) was effective in acute bipolar depression (Calabrese et al, 1999); indeed, lamotrigine is now increasingly accepted as a very effective agent for the depressed phase of bipolar disorder, but its use is limited by its side-effect profile. Lamotrigine is a comparatively novel antiepileptic agent used primarily in the treatment of 
generalized and partial seizures (Bazil, 2002; Kwan and Brodie, 2001); its mechanism of action is considered to be a reduction in glutamate release following inhibition of $\mathrm{Na}^{+}$ channels and consequent neurotransmitter glutamate exocytosis (Ahmad et al, 2004; Lees and Leach, 1993). Riluzole (2-amino-6-trifluoromethoxybenzothiazole), an inhibitor of sodium channel and thus glutamate release, is approved by the US Food and Drug Administration for the treatment of amyotrophic lateral sclerosis (Bensimon et al, 1994). Similar to lamotrigine, it also has anticonvulsant and neuroprotective properties. Recent studies show that riluzole was effective in patients with major (unipolar) and bipolar depression (Zarate et al, 2004; Zarate et al, 2005). Since acute regulation of $\mathrm{Na}^{+}$channels, calcium channels, or glutamate release (Rogawski and Loscher, 2004) does not adequately explain the differing clinical profile of these agents in the treatment of mood disorders, we sought to investigate additional potential mechanisms.

The potential role of glutamatergic system in the pathophysiology of and treatment of mood disorders has been investigated in earnest only recently (Bonanno et al, 2005; Coyle and Duman, 2003; Du et al, 2004; Krystal et al, 2002; Sun et al, 2005). It is noteworthy that a growing body of data suggests that AMPA (-amino-3-hydroxy-5-methylisoxazole-4-propionic acid) receptor trafficking (including receptor insertion, internalization, and delivery to synaptic sites) plays a critical role in regulating activity-dependent regulation of synaptic strength, as well as various forms of neural and behavioral plasticity (Bonanno et al, 2005; Carlezon and Nestler, 2002; Kendell et al, 2005; Malenka, 2003; Rumpel et al, 2005; Sun et al, 2005; Wolf et al, 2004). Three major classes of ionotropic glutamate receptors are expressed throughout the mammalian central nervous system (CNS), including AMPA, kainate, and $N$-methyl-Daspartate (NMDA) receptors. AMPA receptors mediate the majority of excitatory synaptic transmission in the CNS. The AMPA receptor channel is composed of the subunits GluR1, GluR2, GluR3, and GluR4. Emerging data suggest that a modification of the levels of synaptic expression of these subunits is a critically important mechanism for regulating postsynaptic responsiveness at many different synapses. AMPA receptor subunit GluR1 and GluR2 trafficking is regulated by cAMP-dependent protein kinase (PKA), calcium-calmodulin-dependent protein kinase II (CAMKII), PKC, and ERK through phosphorylation of specific sites (Esteban et al, 2003; Lee et al, 1998; Malinow and Malenka, 2002). Notably, many of these cascades are targets for mood-stabilizing agents and antidepressants (Donati and Rasenick, 2003; Manji and Lenox, 2000; Shao et al, 2005). We therefore sought to investigate concurrently the effects of lamotrigine, riluzole, and valproate on surface AMPA receptors, AMPA phosphorylation, and AMPA function.

We have found that the two anticonvulsants lamotrigine and riluzole (with a predominantly antidepressant profile, but possessing structural dissimilarity), when administered chronically at therapeutically relevant concentrations, enhanced AMPA receptor GluR1 and GluR2 distribution on the neuronal surface. The increase in surface GluR1 and GluR2 levels was accompanied by enhanced depolarization of membrane potential. In dramatic contrast, the anticonvulsant valproate (with a predominantly antimanic profile) exerted opposite effects on GluR1 and GluR2 localization. In addition, phosphorylation of GluR1 at S845 site was significantly increased after treatment with lamotrigine and riluzole in vitro and in vivo, while valproate demonstrated an opposite effect at the same site. Finally, chronic in vivo treatment of rodents with the traditional antidepressant imipramine, or riluzole, or lamotrigine, all resulted in increased GluR1 phosphorylation at the S845 site. Together, these data raise the intriguing possibility that chronic effects on AMPA receptor localization may play a role in conferring a predominantly antidepressant or antimanic profile to anticonvulsant agents.

\section{MATERIALS AND METHODS}

\section{Neuronal Culture Preparations}

Cultures of hippocampal neurons were prepared utilizing previously published procedures with minor modifications (Du et al, 2000). Briefly, whole hippocampi were dissected from embryonic day 18 (E18) rats, dissociated in $\mathrm{Ca}^{2+}$ - and $\mathrm{Mg}^{2+}$-free Hank's balance salt solution containing $0.125 \%$ trypsin for $15 \mathrm{~min}$, triturated in DMEM (Invitrogen)/10\% fetal bovine serum, and plated at 0.4 million cells/well in six-well plates. Cells were grown at $37^{\circ} \mathrm{C}, 5 \% \mathrm{CO}_{2}$, and $95 \%$ humidity, first in $10 \%$ fetal bovine serum/DMEM, and switched 1 day later to serum-free medium, neurobasal plus B27 (B27NB, Invitrogen). The cultures were grown in serum-free medium for 8-10 days before the start of experiments, and the medium was changed every 3 days. Fresh medium was applied $24 \mathrm{~h}$ before each experiment. These cultures yielded virtually pure neurons (Supplementary Figure 2). Doses of drugs chosen were based on their therapeutic plasma concentrations clinically (Groeneveld et al, 2003; Hirsch et al, 2004; Zarate et al, 2005). Thus, concentrations of lamotrigine $(20 \mu \mathrm{M})$, riluzole $(2.0 \mu \mathrm{M})$, and valproate $(1.0 \mathrm{mM})$ were chosen for our studies.

\section{Surface Biotinylation and Western Blot Analysis of GluR1 and GluR2}

Surface GluR1 and GluR2 receptors were detected by biotinylation assay followed by Western blot analysis using either an anti-GluR1 or anti-GluR2 antibody (Chemicon), as described. After a 3-day treatment with lamotrigine, riluzole, or valproate, ice-cold phosphate buffer saline (PBS with calcium and magnesium, $\mathrm{pH}$ 7.4, Invitrogen) was added to the cultures to prevent receptor internalization. The cells were washed three times with ice-cold PBS and incubated in Sulfo-NHS-LC-biotin $(0.25 \mathrm{mg} / \mathrm{ml}$ in cold PBS, Pierce) for $30 \mathrm{~min}$. Surface biotinylation was stopped by removing above solution and incubating the cells in $10 \mathrm{mM}$ ice-cold glycine in PBS for $20 \mathrm{~min}$. Cells were then washed three times with cold PBS and harvested with RIPA buffer, containing $20 \mathrm{mM}$ HEPES, pH 7.4, $100 \mathrm{mM} \mathrm{NaCl}$, $1 \mathrm{mM}$ EGTA, $1 \mathrm{mM}$ Na orthovanadate, $50 \mathrm{mM} \mathrm{NaF}, 1 \% \mathrm{NP}$ $40,1 \%$ deoxycholate, $0.1 \%$ SDS, Protease Inhibitor Cocktail (Sigma), Phosphotase Inhibitor Cocktail I (Sigma), and Phosphotase Inhibitor Cocktail II (Sigma). Protein concentrations were determined by BCA protein assay kit (Pierce). Biotinylated proteins were precipitated with $100 \mu \mathrm{l}$ of ImmunoPure Immobilized Streptavidin (Pierce), separated 
on $10 \%$ SDS-PAGE gel, and transferred to nitrocellulose membrane. The membranes were probed with a polyclonal anti-GluR1 or anti-GluR2 antibodies (1:200, Chemicon), followed by peroxidase-conjugated goat anti-rabbit IgG (1:3000, Vector). Immunoreactive bands were visualized by enhanced chemiluminescence (ECL, Amersham). The ECL signal intensities were quantified with the Kodak Image program.

In order to measure the GluR1 phosphorylation of GluR1 at the PKA site and the total amount of GluRs, cultured hippocampal neurons were harvested with RIPA buffer containing protease inhibitors and phosphatase inhibitors after treatment with drugs with the concentrations indicated. The protein concentrations were determined by BCA protein assay kit (Pierce). Equal amounts of cell homogenates were separated by electrophoresis. We used $10 \mu \mathrm{g}$ for the cell lysates which is within the linear rage (Supplementary Figure 1). Western blot analysis was performed with anti-phospho-GluR1 (S845) antibody (Covance) or anti-actin antibody (Sigma). The membrane was then stripped and Western blot analysis of GluR1 was performed. Quantitation for each experimental condition was based on 3-6 independent experiments (samples); each was repeated at least 2-3 times. The results were pooled and averaged, and presented as mean \pm SE. The data were analyzed by Student's $t$-test.

\section{Measurement of Membrane Potential Changes by $\operatorname{DiBAC}_{4}(3)$}

Hippocampal neurons were cultured for 10 days and treated with either lamotrigine $(20 \mu \mathrm{M})$ or riluzole $(2 \mu \mathrm{M})$ for additional 3 days. The neurons were then preincubated in MIC buffer ( $\mathrm{NaCl} 130 \mathrm{mM}, \mathrm{KCl} 5.3 \mathrm{mM}, \mathrm{MgSO}_{4} 0.8 \mathrm{mM}$, $\mathrm{Na}_{2} \mathrm{HPO}_{4} 1 \mathrm{mM}$, glucose $2 \mathrm{mM}$, HEPES $20 \mathrm{mM}$, Na-pyruvate $1 \mathrm{mM}, \mathrm{NaHCO}_{3} 2.5 \mathrm{mM}$, ascorbic acid $1.0 \mathrm{mM}, \mathrm{CaCl}_{2}$ $1.5 \mathrm{mM}$, BSA $1.5 \mathrm{mg} / \mathrm{ml}$ ) containing the corresponding drugs such as lamotrigine or riluzole for $30 \mathrm{~min}$. The buffer was then changed to $1350 \mu \mathrm{l}$ of $500 \mathrm{nM} \operatorname{DiBAC}_{4}(3)$ (Anaspec) containing buffer. After a 10-min incubation, images were acquired by Zeiss LSM 510 confocal microscope. One hundred and fifty microliters of $10 \mu \mathrm{M}$ AMPA solution were applied to the neurons to reach the final concentration of $1 \mu \mathrm{M}$ in the solution. Fields for image were random. Images were captured every $10 \mathrm{~s}$ for $7-14 \mathrm{~min}$ by Zeiss LSM 510 confocal microscopy. Fluorescence was excited at $488 \mathrm{~nm}$ and emission was measured at $505 \mathrm{~nm}$. The intensity of each neuron was quantified by Zeiss LSM 510 program. The experiments were repeated independently for three times and peak value data were combined for all three experiments. Data were analyzed by Dunnett's multiple comparison test.

\section{Animal Treatment and Sample Analysis}

C57BL/6 mice were obtained from a breeding colony from Taconic Farm. Animals were group housed ( $n=4 /$ cage) in polypropylene cages, and maintained on a 12-h light/dark cycle at $25^{\circ} \mathrm{C}$ and had free access to water and chow. Lamotrigine $(25 \mathrm{mg} / \mathrm{kg}$, once daily), riluzole, $(10 \mathrm{mg} / \mathrm{kg}$, once daily), or imipramine (10 $\mathrm{mg} / \mathrm{kg}$, twice daily) were dissolved in $3 \%$ of total volume of DMSO and then $0.5 \%$ of
Tween 80 in saline and injected (intraperitoneally) into the animals for 10 days $(N=6$ animals per group for lamotrigine and riluzole; and $N=11$ animals for imipramine (impramine treatment was undertaken for another biochemical assay as well, resulting in the larger sample size)) (Boireau et al, 2000; Szymczyk and ZebrowskaLupina, 2000). The hippocampi from the mouse brains were removed immediately after decapitation, immersed in liquid nitrogen, placed in labeled Eppendorf tubes on dry ice, and then stored and kept frozen at $-70^{\circ} \mathrm{C}$ until processing. The samples were sonicated in homogenization buffer A $(50 \mathrm{mM}$ Tris-Cl, $\mathrm{pH} 7.5$, containing $2 \mathrm{mM}$ dithiothreitol, $2 \mathrm{mM}$ EDTA, 2 mM EGTA, $50 \mu \mathrm{M}$ 4-(2-aminoethyl)-benzenesulfonylfluoride hydrochloride, $50 \mathrm{mM} \mathrm{KF}, 50 \mathrm{nM}$ okadaic acid, $1 \mathrm{mM}$ sodium orthovanadate, $5 \mathrm{mM}$ sodium pyrophosphate, $0.1 \% \mathrm{NP}-40$, and $5 \mu \mathrm{g} / \mathrm{ml}$ each of leupeptin, aprotinin, chymostatin, and pepstatin A), spun in the Eppendorf 5810R centrifuge for $20 \mathrm{~min}$ at $4^{\circ} \mathrm{C}$ at 20000 r.c.f., and the clear homogenate used for (1) protein determination, (2) immunoblot analysis of phosphorylated, and total GluR1 levels in the hippocampus. Protein concentrations were determined using the BCA assay kit; the linearity of the protein concentration for immunoblotting was ascertained by resolution of selected concentrations of protein. Equal amounts of proteins were subjected to 10\% SDS-PAGE gels and separated by electrophoresis. Proteins were then electrophoretically transferred to nitrocellulose membranes. Nonspecific binding on the nitrocellulose was blocked with Tris-buffered saline plus Tween 20 (TBST), 10\% nonfat dry milk, and then incubated with anti-phospho-GluR1S845 antibody. The secondary antibodies were horseradish peroxidase (HRP)-conjugated anti-mouse IgG or HRPanti-rabbit IgG. The ECL plus kit was used as a detection system. Of note, in these experiments, nitrocellulose membranes were first probed with anti-phospho-GluR1S845 antibody and then stripped with stripping buffer and reprobed with anti-GluR1 antibody. The bottom part of the same membrane was used for Western blot analysis of actin (Sigma) to assure that equal amount of protein was loaded to the wells. The significance of each groups were tested by Student's $t$-test.

\section{RESULTS}

\section{Lamotrigine and Riluzole Treatments Enhance Surface Expression of GluR1 in Cultured Hippocampal Neurons, while Valproate Treatment Reduces it}

Hippocampal neuronal cultures were prepared from E18 embryo to yield a pure neuron population and cultured for 8-10 days to gain synaptic neuronal connections. We chose therapeutically relevant concentrations of $20 \mu \mathrm{M}$ for lamotrigine and 2.0 for riluzole, based on patient's serum concentrations. Different doses of lamotrigine $(4,20$, $100 \mu \mathrm{M})$, riluzole $(0.4,20,100 \mu \mathrm{M})$, or valproate $(1.0 \mathrm{mM})$ were applied to cultured hippocampal neurons, and the surface GluR1 levels were then determined by biotinylation assay. Both lamotrigine and riluzole significantly enhanced GluR1 surface expression after 3 days of treatment, with maximum increase of 168 and $156 \%$, respectively (Figure 1a-e). We also determined the time course for riluzole and lamotrigine in therapeutically relevant concentrations. Cells 

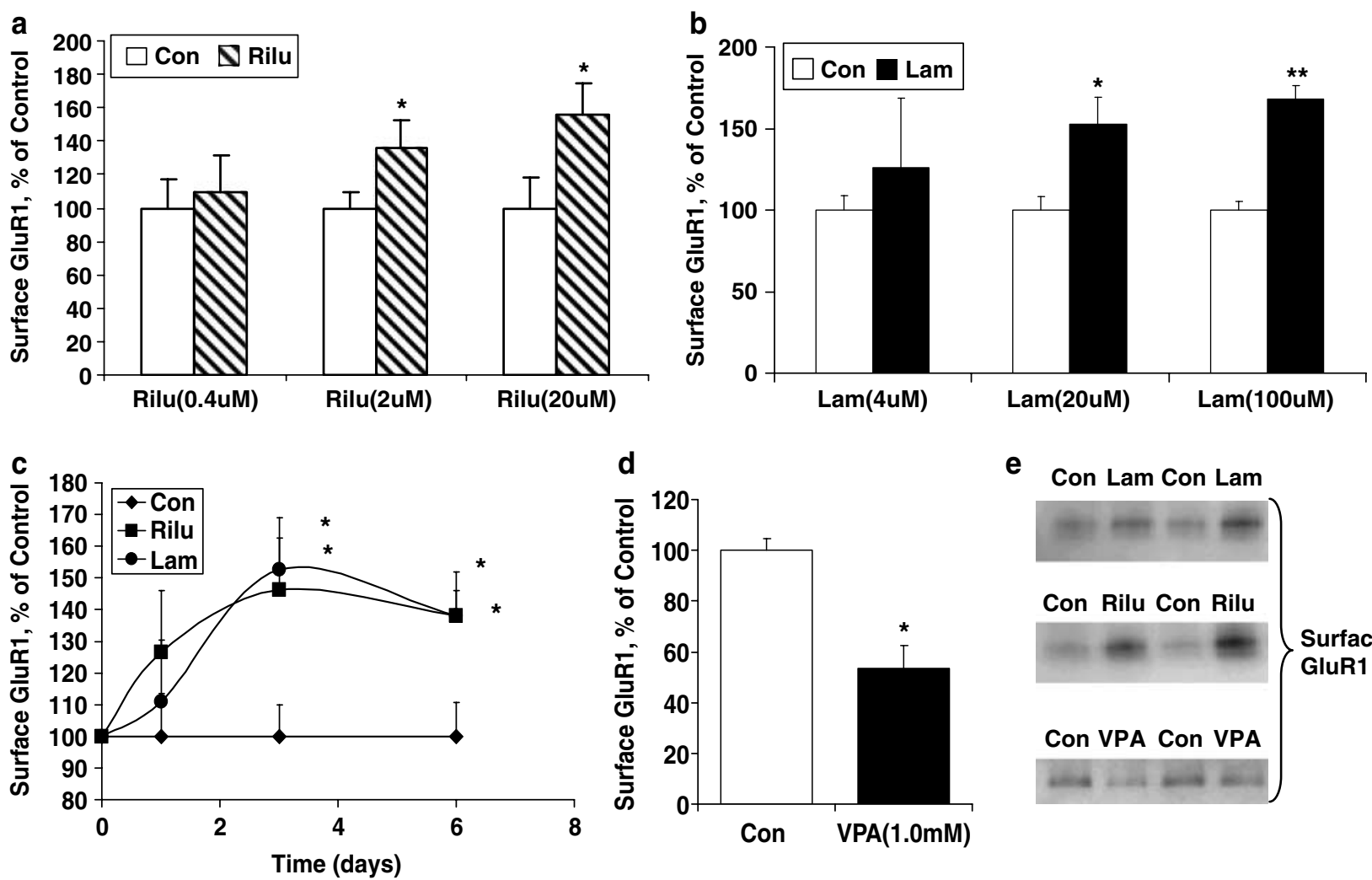

e Con Lam Con Lam

Figure I Lamotrigine and riluzole treatments enhance surface expression of GluRI in cultured hippocampal neurons, while valproate treatment reduces it. Hippocampal primary culture neurons were prepared from EI 8 Sprague-Dawley embryos. After 8-10 days of culturing in B27-neurobasal media, neurons were treated with lamotrigine (Lam), or riluzole (Ril), or valproate (VPA) in the concentrations and for the times indicated. Surface proteins of the neurons were labeled with biotin and the cells were then harvested with RIPA buffer. Biotinylated surface proteins were precipitated by immobilized-avidin and analyzed by Western blot analysis with anti-GluRI antibody. Data were analyzed by Kodak imaging system and were pooled from 2-3 independent experiments and presented as mean $+S E\left(n=9-1\right.$ I, Student's t-test, ${ }^{*} p<0.05$, ** $p<0.01$ ). (a) Dose dependency for riluzole treatment on surface GluRI in cultured hippocampal neurons after $\overline{3}$ days of treatment. (b) Dose dependency for lamotrigine treatment on surface GluRI in cultured hippocampal neurons after 3 days of treatment. (c) Time course after treatment of lamotrigine $(20 \mu \mathrm{M})$ and riluzole $(2.0 \mu \mathrm{M})$ on surface GluRI in cultured hippocampal neurons. (d) Effect of valproate $(1.0 \mathrm{mM}$ ) on surface GluRI after 3-day treatment in cultured hippocampal neurons. (e) Samples of Western blot analysis of surface GluRI after therapeutically relevant concentrations of lamotrigine $(20 \mu \mathrm{M})$, riluzole $(2.0 \mu \mathrm{M})$, and valproate $(1.0 \mathrm{mM})$ treatments.

treated with lamotrigine $(20 \mu \mathrm{M})$ and riluzole $(2 \mu \mathrm{M})$ significantly enhanced GluR1 on the surface after 3 days, effects that were sustained through 6 days (Figure 1c). In dramatic contrast, valproate reduced surface GluR1 levels to $53.6 \%$ after 3 days of treatment (Figure $1 \mathrm{~d}$ and e).

\section{Lamotrigine and Riluzole Treatments Enhance Surface Expression of GluR2 in Cultured Hippocampal Neurons, while Valproate Treatment Reduces it}

GluR1 and GluR2 form heterotetramers; thus, we next sought to determine whether GluR2 surface expression is also altered by these treatments. Hippocampal neurons were treated with lamotrigine $(4,20,100 \mu \mathrm{M})$, or riluzole $(0.4,2.0$, $20 \mu \mathrm{M})$, or valproate $(1.0 \mathrm{mM})$ for 3 days. Surface GluR2 levels were determined by biotinylation assay. Both lamotrigine and riluzole significantly enhanced GluR2 surface expression in a dose- and time-dependent manner, with the maximum increase of 225 and $213 \%$, respectively (Figure 2a, b, and e). Notably, lamotrigine and riluzole enhanced GluR2 surface expression in the therapeutically relevant concentrations to 153 and $146 \%$, respectively, after 3 days of treatment, and these effects sustained through 6 days (Figure 2c). Once again, in dramatic contrast, valproate $(1 \mathrm{mM})$ reduced surface GluR2 levels to $60.9 \%$ after 3 days of treatment (Figure $2 \mathrm{~d}$ and e).

\section{Membrane Depolarization is Significantly Increased with AMPA Stimulation after Riluzole and Lamotrigine Treatments}

Next, we investigated the functional consequence of the increased number of AMPA receptors on the neuronal surface after treatment with either lamotrigine or riluzole. Hippocampal neurons were cultured for 10 days and treated with riluzole $(2.0 \mu \mathrm{M})$ and lamotrigine $(20 \mu \mathrm{M})$ for 3 additional days. The cells were incubated with $\operatorname{DiBAC}_{4}(3)$ dye and their membrane potentials were determined by fluorescent color changes after AMPA stimulation. TTX $(10 \mu \mathrm{M})$ was applied to the hippocampal neurons to stop the spontaneous activity. AMPA-induced depolarization was significantly higher in the lamotrigineand riluzole-treated groups (Figure $3 \mathrm{a}$ and $\mathrm{b}$ ). The peak values of depolarization in riluzole- and lamotrigine-treated group were 150.6 and $130.6 \%$ of control, respectively (Figure 3c). 

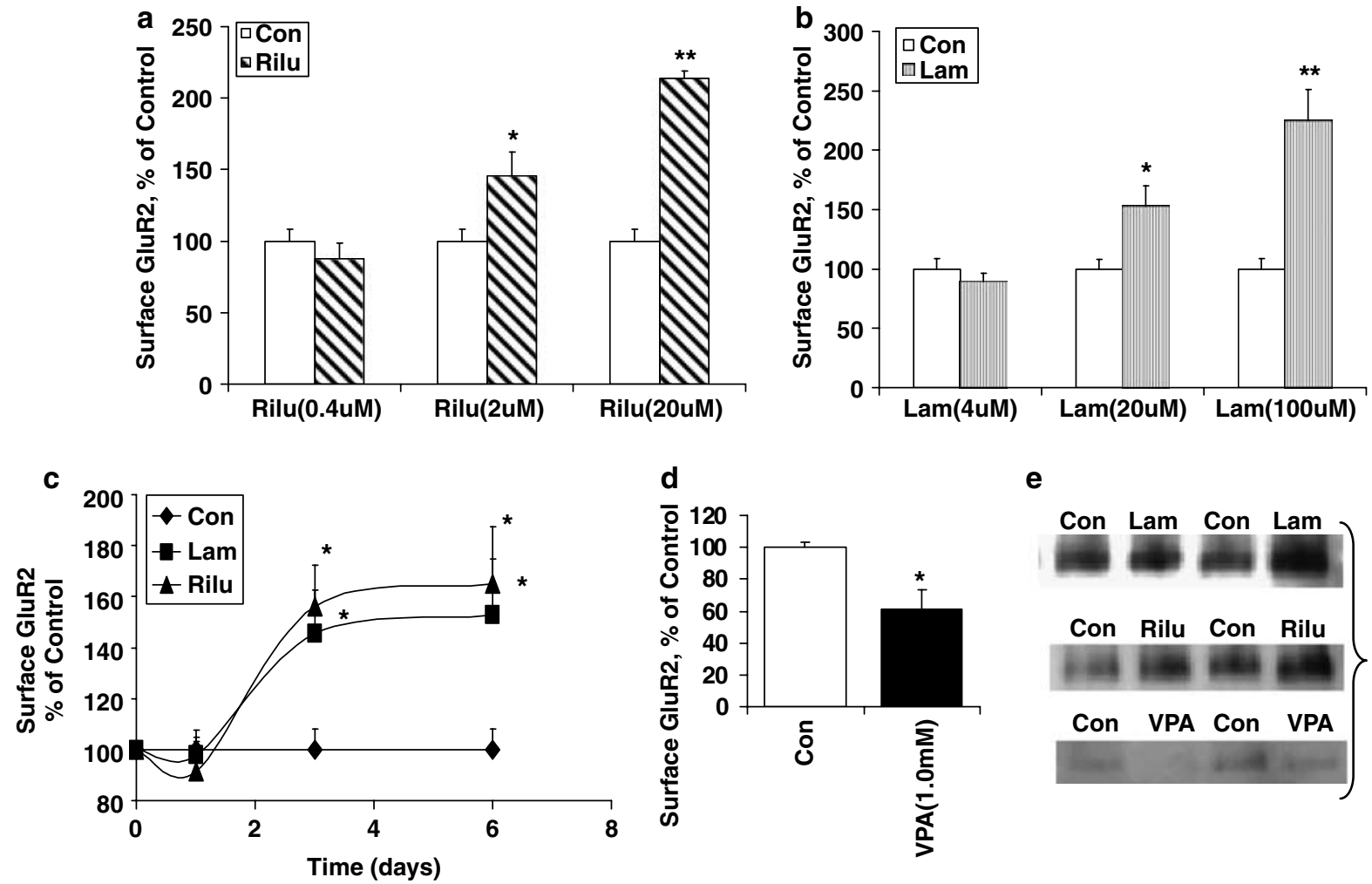

e

Figure 2 Lamotrigine and riluzole treatments enhance surface expression of GluR2 in cultured hippocampal neurons, while valproate treatment reduces it. Hippocampal neurons were treated with lamotrigine, or riluzole, or valproate for the times and doses indicated. Biotinylated surface proteins were precipitated by immobilized-avidin and analyzed by Western blot analysis with anti-GluR2 antibody. Data were analyzed by Kodak imaging system and were pooled from 2-3 independent experiments and presented as mean $+S E(n=6-10$, Student's $t$-test, $* p<0.05$, $* * *<<0.01)$. (a) Dose dependency for riluzole treatment on surface GluR2 in cultured hippocampal neurons after 3 days of treatment. (b) Dose dependency for lamotrigine treatment on surface GluR2 in cultured hippocampal neurons after 3 days of treatment. (c) Time course after treatment of lamotrigine $(20 \mu \mathrm{M})$ and riluzole $(2.0 \mu \mathrm{M})$ on surface GluR2 in cultured hippocampal neurons. (d) Effect of valproate (1.0 mM) on surface GluR2 after 3-day treatment in cultured hippocampal neurons. (e) Samples of Western blot analysis of surface GluR2 after therapeutically relevant concentrations of lamotrigine $(20 \mu \mathrm{M})$, riluzole $(2.0 \mu \mathrm{M})$, and valproate $(1.0 \mathrm{mM})$ treatments.

Phosphorylation of GluR1 S845 at PKA Site is Significantly Enhanced after Lamotrigine or Riluzole Treatment, but Reduced by Valproate Treatment

Previous studies show that the phosphorylation of GluR1 at the PKA site (S845) is an essential mechanism to regulate GluR1/2 receptor insertion onto the neuronal surface (Esteban et al, 2003; Smith et al, 2006). We therefore sought to determine whether the phosphorylation of GluR1 at the PKA site was altered, or not, after the treatment. We found that both lamotrigine $(20 \mu \mathrm{M})$ and riluzole $(2.0 \mu \mathrm{M})$ treatments significantly enhanced the GluR1 phosphorylation at the PKA site to 156 or $130 \%$, respectively, whereas valproate significantly reduced GluR1 phosphorylation at PKA site to $58.5 \%$ (Figure 4). Actin was utilized as a loading control (Figure 4c).

Total GluR1 and GluR2 Expression Levels are Increased in Riluzole-Treated but not Lamotrigine-Treated Hippocampal Neurons

In order to determine if the increased surface levels of GluR1 and GluR2 were accompanied by increases in total GluR1 and GluR2 protein levels, the total levels of these proteins were determined after chronic lamotrigine or riluzole. Total GluR1 levels were enhanced after riluzole treatment (145\%), but remained unchanged after lamotrigine and valproate treatments (Figure 5a). Similarly, total GluR2 levels were also increased significantly in riluzoletreated cortical neurons (145\%), but remained unchanged in lamotrigine- and riluzole-treated cortical neurons (Figure 5b). In conclusion, while both riluzole and lamotrigine increased GluR1 phosphorylation and surface levels, only riluzole enhanced total GluR1and GluR2 expression.

\section{Phosphorylation of GluR1 (S845) is also Significantly Increased In Vivo after Lamotrigine and Riluzole Treatments, as well as Traditional Antidepressant Imipramine Treatments}

Finally, we sought to determine if riluzole or lamotrigine regulated GluR1 levels after chronic in vivo treatment of rodents. Furthermore, we compared the effects of these anticonvulsants to the effects of the traditional antidepressant, imipramine. Phosphorylation of hippocampal GluR1 (S845) was significantly increased after in vivo treatment with lamotrigine $(128 \%)$, riluzole $(147 \%)$, or imipramine $(140 \%)$ treatment (Figure 6a). Total GluR1 levels remained unchanged in vivo (Figure $6 \mathrm{~b}$ ). 

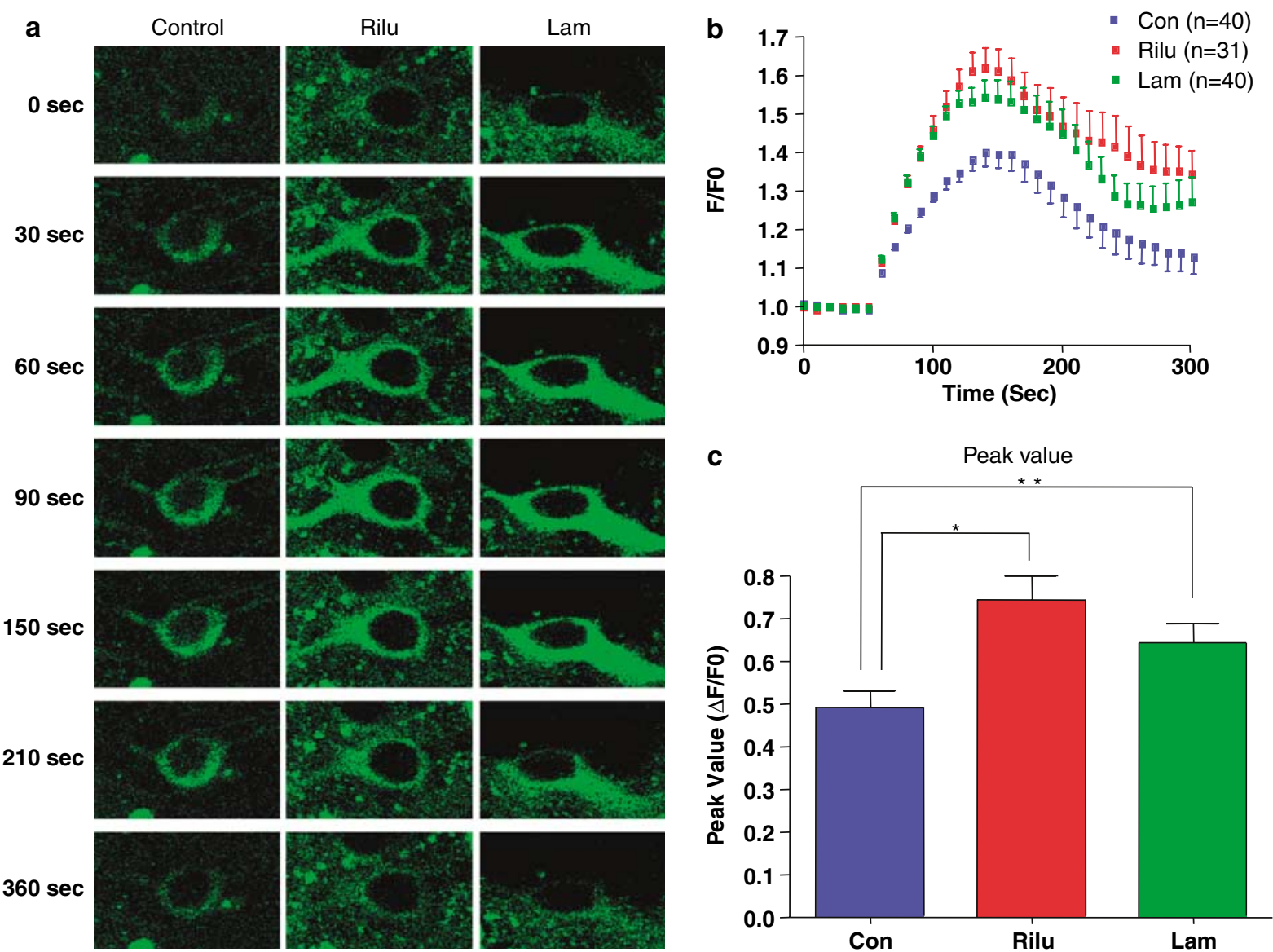

Figure 3 Membrane depolarization is significantly increased with AMPA stimulation after riluzole and lamotrigine treatments. Hippocampal neurons were cultured for 10 days and treated with lamotrigine and riluzole for additional 3 days. The AMPA (I.0 $\mu \mathrm{M})$-induced depolarization of membrane potential was determined by a fluorescent dye $\mathrm{DiBAC}_{4}(3)$ in the presence of TTX $(10 \mu \mathrm{M})$ to control spontaneous activity. Data were analyzed by Dunnett's multiple comparison test (number of experiments $(N)=3$; number of cells $(n)=31-40$, $* p<0.05$, $* * p<0.01$ ) (a) The time course of membrane depolarization after AMPA stimulation in lamotrigine- or riluzole-treated hippocampal neurons. (b) The quantification of membrane depolarization after AMPA stimulation in lamotrigine- or riluzole-treated neurons. (c) Peak values of membrane depolarization after AMPA stimulation in lamotrigine- and riluzole-treated hippocampal neurons.

\section{DISCUSSION}

In this study, we sought to determine the effects of three anticonvulsants on surface AMPA receptors and the relationship to the clinical profile of these agents in the treatment of mood disorders. We found that the agents with a predominantly antidepressant profile, namely lamotrigine and riluzole, significantly enhanced surface expression of GluR1 and GluR2 in a time- and dose-dependent manner. By contrast, the anti-manic agent valproate significantly reduced surface expression of GluR1 and GluR2. Furthermore, the increase in surface GluR1 and GluR2 receptors was accompanied by increased AMPA-mediated membrane depolarization in the lamotrigine- or riluzole-treated hippocampal neurons. Phosphorylation of GluR1 at PKA site was enhanced in both lamotrigine- and riluzole-treated hippocampal neurons, whereas it was reduced in valproatetreated hippocampal neurons. In addition, phosphorylation of hippocampal GluR1 at its PKA site (often viewed as an indicator for GluR1 membrane insertion in neurons) was significantly increased after chronic in vivo treatment with lamotrigine, riluzole, and the traditional antidepressant, imipramine. These results raise the intriguing possibility that delayed changes in GluR1/2 phosphorylation and surface levels may play a role in conferring antidepressant/antimanic profiles to these agents.

\section{Anticonvulsants as Drugs for Mood Disorders: Diverse Effects and Clinical Relevance}

The anticonvulsant drugs studied all inhibit excessive neuronal activity; this acute effect appears to be produced by several mechanisms including blockage of voltage-gated sodium channels, or inhibition of excitatory glutamatergic neurotransmission. It is quite likely that many of the acute beneficial effects of these agents in the treatments of epilepsy can be explained by these direct-acting mechanisms. By contrast, the fact that these agents require chronic administration for therapeutic effects, and the fact that they have fairly distinct clinical profiles in the treatment of mood disorders suggests that other mechanisms must also be operative.

In view of the critical role of AMPA receptor localization in regulating various forms of plasticity, our laboratory has 

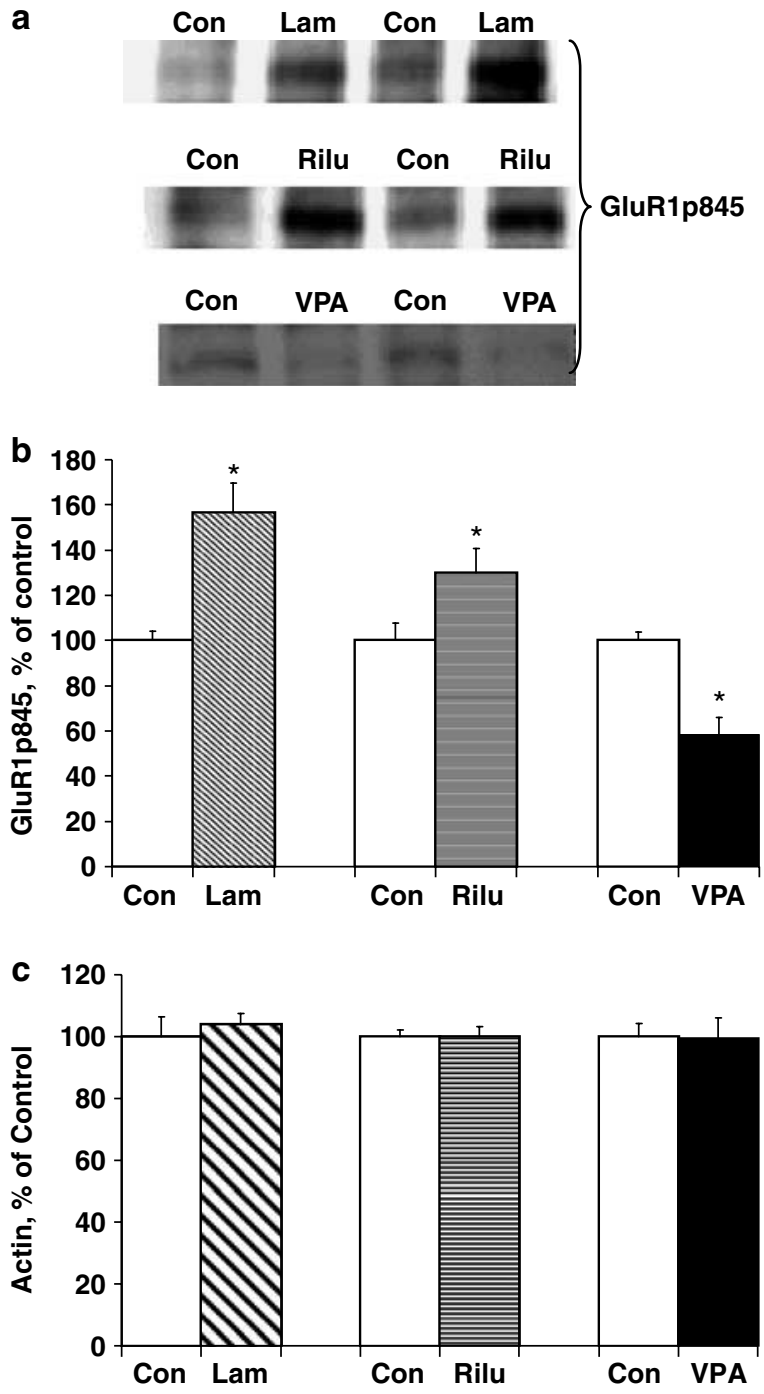

Figure 4 Phosphorylation of GluRI at PKA site S845 is enhanced after lamotrigine or riluzole treatment, but reduced after valproate treatment. Hippocampal neurons were treated with lamotrigine $(20 \mu \mathrm{M})$, or riluzole $(2.0 \mu \mathrm{M})$, or valproate $(1.0 \mathrm{mM})$ for 3 days. Proteins were harvested and equal amounts of proteins were loaded on the gel for electrophoresis. Western blot analysis was performed with anti-GluRIp845 antibody and anti-actin antibody. (a) Phosphorylation of GluRI (S845) after lamotrigine, riluzole, and valproate treatments. (b) Actin was not changed in samples among the three treatment groups. Data were pooled from 2-3 independent experiments and presented as mean \pm SE $(n=7-\mid 1$, Student's t-test, $\left.{ }^{*} p<0.05\right)$.

been investigating the potential role of AMPA receptor trafficking in mediating the therapeutic effects of antimanic agents. We found that the structurally highly dissimilar antimanic agents, namely lithium and valproate, have a common effect on downregulating AMPA GluR1 synaptic expression in the hippocampus after prolonged treatment with therapeutically relevant concentrations as assessed both in vitro and in vivo (Du et al, 2004). Notably, the antidepressant imipramine has an opposite effect as it upregulates AMPA receptors in the hippocampus (Du et al, 2003; Gray et al, 2003). These latter results are also consistent with the studies from the Greengard laboratory,
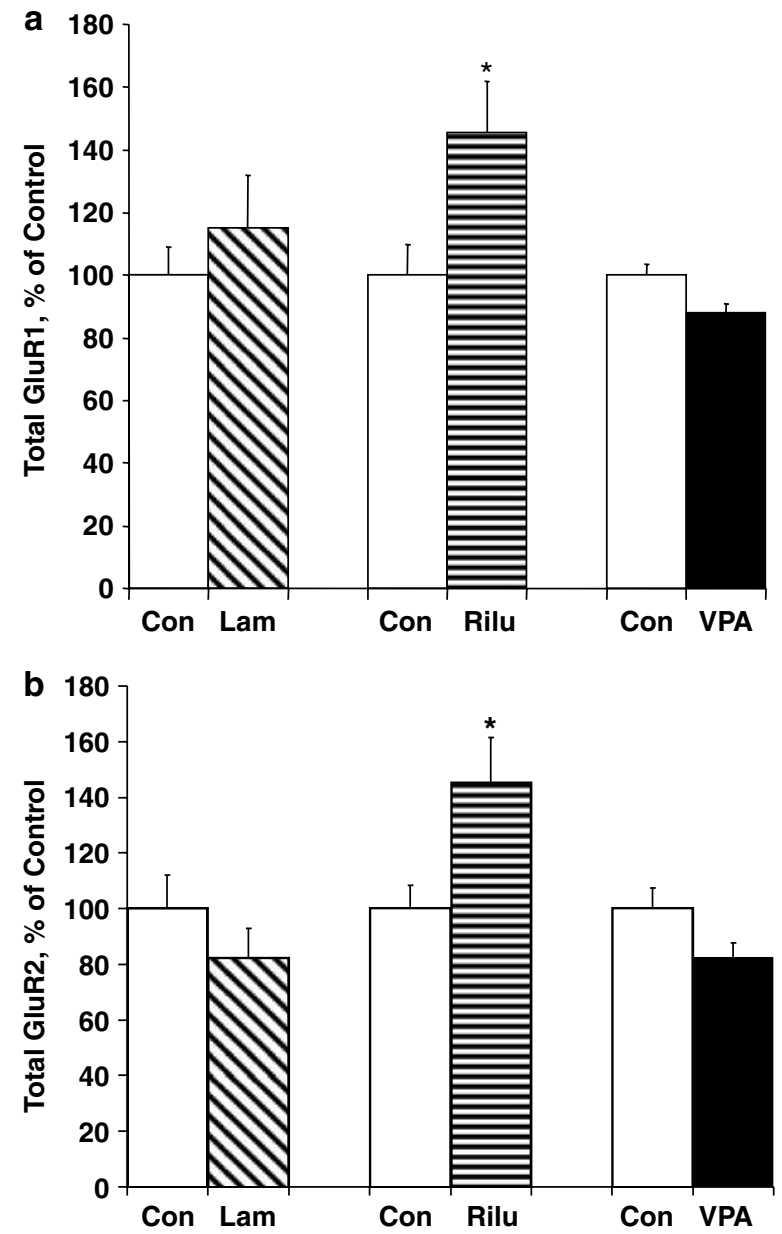

Figure 5 Total GluRI and GluR2 levels in cultured hippocampal neurons after riluzole and lamotrigine treatments. Hippocampal neurons were treated with lamotrigine $(20 \mu \mathrm{M})$, riluzole $(2.0 \mu \mathrm{M})$, or valproate $(1.0 \mathrm{mM})$ for 3 days. Proteins were harvested and equal amount of proteins were loaded onto the gel for electrophoresis. Western blot analysis was performed with and anti-GluRI (a) and anti-GluR2 (b) antibody. Data were pooled from $2-3$ independent experiments and presented as mean \pm SE $\left(n=8-14\right.$, Student's $t$-test, $\left.{ }^{*} p<0.05\right)$.

demonstrating that chronic fluoxetine significantly enhanced GluR1 phosphorylation (S845) of GluR1 in the hippocampus (Svenningsson et al, 2002).

AMPA Receptor Phosphorylation at PKA Site Regulates Membrane Insertion of AMPA Receptors and Enhances the Depolarization of the Neuronal Membranes

A number of studies indicate that the synaptic delivery of different subunit combinations is governed by molecular rules encoded in the intracellular C-terminals of the receptor subunits. Phosphorylation of serines 831 and 845 (S831 and S845) in the GluR1 subunit by CaMKII and PKA, respectively, regulates the ion channel properties and synaptic trafficking of GluR1-containing AMPA receptors during hippocampal long-term potentiation (Roche et al, 1996; Barria et al, 1997; Mammen et al, 1997; Derkach et al, 1999; Banke et al, 2000; Lee et al, 2000; Esteban et al, 2003). Dephosphorylation of the GluR1 at the PKA site by protein 

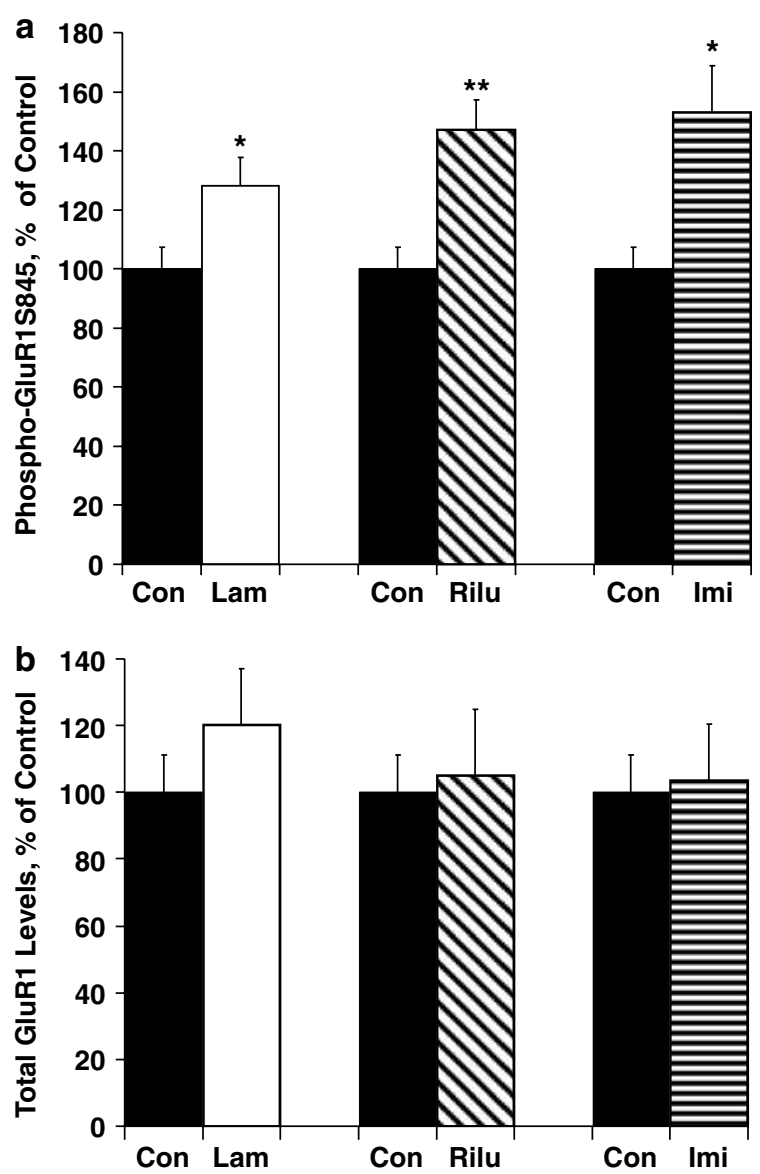

Figure 6 Chronic treatment with lamotrigine, riluzole, and imipramine in vivo significantly enhance GluRI phosphorylation at S845. C57/BL/6 mice were treated with lamotrigine (Lam (6), $25 \mathrm{mg} / \mathrm{kg}$, once daily), riluzole (Rilu (6), $10 \mathrm{mg} / \mathrm{kg}$, once daily), and imipramine (Imi (I I), $10 \mathrm{mg} / \mathrm{kg}$, twice daily) for 10 days. Hippocampi were isolated from the brain tissue and protein samples were prepared from these brain tissues. Equal amount of proteins were loaded on 10\% SDS-PAGE. Phosphorylation of GluRI S845 was determined by Western blot analysis with an anti-GluRIS845 antibody (a). Total GluRI were determined and showed no changes among three groups (b). Chronic lamotrigine-, riluzole-, or imipramine-treated animals all showed significantly increased levels of pGluRI at the S845 site $(* p<0.05$, *** $p<0.01)$.

phosphatases (eg, calcineurin and PP1) targets GluR1 for recycling endosomes during long-term depression, while re-phosphorylation by PKA may target the receptor for reinsertion into the membrane (Banke et al, 2000). In activity-dependent regulation of subunit-specific AMPA receptor trafficking, GluR1 is the critical subunit that 'drives' AMPA receptors to the surface and to synapses in response to NMDA receptor stimulation and activation of CaMKII, resulting in synaptic potentiation (Hayashi et al, 2000). Specifically, activity-dependent movement into synapses were governed by two steps: (1) insertion of GluR1/GluR2 onto the neuronal surface is governed by phosphorylation of GluR1 on its PKA site (GluR1, S845); and (2) GluR1/GluR2 movement into synapses is regulated by the synaptic activity via activation of CaMKII and MAP kinase (Hayashi et al, 2000; Lee et al, 2000). In this study, we found that phosphorylation of GluR1 at PKA site is significantly increased in vitro and in vivo in lamotrigineand riluzole-treated groups, effects that may mechanistically underlie the enhancement of GluR1 and GluR2 membrane localization.

\section{AMPA Receptors and Affective-Like Behavior}

Interestingly, emerging animal behavioral studies also suggest that facilitating AMPA receptor throughput may be associated with antidepressant-like effects, whereas attenuating it results in antimanic-like effects (as assessed by stimulant-induced hyperactivity and measures of hedonic activity - cardinal symptoms of the manic syndrome) (Choi et al, 2005; Kaddis et al, 1995; Li et al, 1997; Ossowska et al, 2004; Vanover, 1998). Several classes of compounds can allosterically modulate AMPA receptors. These compounds (so-called AMPA receptor-positive modulators or AMPA receptor potentiators, ARPs) do not activate AMPA receptors themselves, but slow the rate of receptor desensitization and/or deactivation in the presence of an agonist (eg, glutamate and AMPA). Studies have shown that the biarylpropylsulfonamide ARPs (LY392098 and LY451616) have antidepressant effects in animal models of depression (including the application of inescapable stressors, forced-swim test, and tail-suspension-induced immobility tests), in learned-helplessness models of depression, and in animals exposed to chronic mild stress procedure (Alt et al, 2005; Li et al, 2001), Moreover, Ampalex was reported to have more rapid effect (during the first week of treatment) than fluoxetine (after 2 weeks) (Knapp et al, 2002). It is note worthy that lamotrigine has been shown to have an antidepressant effect in forced-swim test animal models (Szymczyk and Zebrowska-Lupina, 2000).

In conclusion, we have shown that chronic administration of two structurally dissimilar anticonvulsants with a predominantly antidepressant profile increases surface AMPA receptor levels and GluR1 phosphorylation at its PKA site in vitro and in vivo, whereas an agent with greatest efficacy in the treatment of mania reduces it. In toto, combined with the behavioral data (vide supra), biochemical data suggest that AMPA receptor localization may play an important role in the antidepressant actions. It is thus noteworthy that clinical studies of CNS-penetrant AMPAkines are currently underway (Black, 2005). In view of the critical roles of AMPA receptors in regulating neural and behavioral plasticity, agents capable of directly modulating AMPA receptor throughput may represent exciting novel agents for the treatment of severe mood disorders.

\section{ACKNOWLEDGEMENTS}

We acknowledge the support of the Intramural Research Program of the National Institute of Mental Health and the Stanley Medical Research Institute. Holly Giesen provided outstanding editorial assistance.

\section{REFERENCES}

Ahmad S, Fowler LJ, Whitton PS (2004). Effects of acute and chronic lamotrigine treatment on basal and stimulated extracellular amino acids in the hippocampus of freely moving rats. Brain Res 1029: 41-47. 
Alt A, Witkin JM, Bleakman D (2005). AMPA receptor potentiators as novel antidepressants. Curr Pharm Des 11: 1511-1527.

Banke TG, Bowie D, Lee H, Huganir RL, Schousboe A, Traynelis SF (2000). Control of GluR1 AMPA receptor function by cAMPdependent protein kinase. J Neurosci 20: 89-102.

Barria A, Derkach V, Soderling T (1997). Identification of the $\mathrm{Ca}^{2+}$ / calmodulin-dependent protein kinase II regulatory phosphorylation site in the alpha-amino-3-hydroxyl-5-methyl-4-isoxazolepropionate-type glutamate receptor. J Biol Chem 272: 3272732730.

Bazil CW (2002). New antiepileptic drugs. Neurologist 8: 71-81.

Bensimon G, Lacomblez L, Meininger V (1994). A controlled trial of riluzole in amyotrophic lateral sclerosis. ALS/Riluzole Study Group. N Engl J Med 330: 585-591.

Black MD (2005). Therapeutic potential of positive AMPA modulators and their relationship to AMPA receptor subunits. A review of preclinical data. Psychopharmacology (Berlin) 179: 154-163.

Boireau A, Dubedat P, Bordier F, Imperato A, Moussaoui S (2000). The protective effect of riluzole in the MPTP model of Parkinson's disease in mice is not due to a decrease in MPP(+) accumulation. Neuropharmacology 39: 1016-1020.

Bonanno G, Giambelli R, Raiteri L, Tiraboschi E, Zappettini S, Musazzi L et al (2005). Chronic antidepressants reduce depolarization-evoked glutamate release and protein interactions favoring formation of SNARE complex in hippocampus. J Neurosci 25: 3270-3279.

Calabrese JR, Bowden CL, Sachs GS, Ascher JA, Monaghan E, Rudd GD (1999). A double-blind placebo-controlled study of lamotrigine monotherapy in outpatients with bipolar I depression. Lamictal 602 Study Group. J Clin Psychiatry 60: 79-88.

Carlezon Jr WA, Nestler EJ (2002). Elevated levels of GluR1 in the midbrain: a trigger for sensitization to drugs of abuse? Trends Neurosci 25: 610-615.

Choi KH, Clements RL, Greenshaw AJ (2005). Simultaneous AMPA/kainate receptor blockade and dopamine $\mathrm{D}(2 / 3)$ receptor stimulation in the nucleus accumbens decreases brain stimulation reward in rats. Behav Brain Res 158: 79-88.

Coyle JT, Duman RS (2003). Finding the intracellular signaling pathways affected by mood disorder treatments. Neuron 38: $157-160$.

Derkach V, Barria A, Soderling TR (1999). $\mathrm{Ca}^{2+} /$ calmodulin-kinase II enhances channel conductance of alpha-amino-3-hydroxy5-methyl-4-isoxazolepropionate type glutamate receptors. Proc Natl Acad Sci USA 96: 3269-3274.

Donati RJ, Rasenick MM (2003). G protein signaling and the molecular basis of antidepressant action. Life Sci 73: 1-17.

$\mathrm{Du}$ J, Feng L, Yang F, Lu B (2000). Activity- and Ca(2+)-dependent modulation of surface expression of brain-derived neurotrophic factor receptors in hippocampal neurons. J Cell Biol 150: 1423-1434.

Du J, Gray NA, Falke C, Yuan P, Szabo S, Manji HK (2003). Structurally dissimilar antimanic agents modulate synaptic plasticity by regulating AMPA glutamate receptor subunit GluR1 synaptic expression. Ann NY Acad Sci 1003: 378-380.

Du J, Gray NA, Falke CA, Chen W, Yuan P, Szabo ST et al (2004). Modulation of synaptic plasticity by antimanic agents: the role of AMPA glutamate receptor subunit 1 synaptic expression. J Neurosci 24: 6578-6589.

Ernst CL, Goldberg JF (2003). Antidepressant properties of anticonvulsant drugs for bipolar disorder. J Clin Psychopharmacol 23: 182-192.

Esteban JA, Shi SH, Wilson C, Nuriya M, Huganir RL, Malinow R (2003). PKA phosphorylation of AMPA receptor subunits controls synaptic trafficking underlying plasticity. Nat Neurosci 6: 136-143.
Evins AE (2003). Efficacy of newer anticonvulsant medications in bipolar spectrum mood disorders. J Clin Psychiatry 64(Suppl 8): 9-14.

Gray NA, Du J, Falke CS, Yuan P, Manji HK (2003). Lithium regulates total and synaptic expression of the AMPA glutamate receptor GluR2 in vitro and in vivo. Ann NY Acad Sci 1003: 402-404.

Groeneveld GJ, Van Kan HJ, Kalmijn S, Veldink JH, Guchelaar HJ, Wokke JH et al (2003). Riluzole serum concentrations in patients with ALS: associations with side effects and symptoms. Neurology 61: 1141-1143.

Hayashi Y, Shi SH, Esteban JA, Piccini A, Poncer JC, Malinow R (2000). Driving AMPA receptors into synapses by LTP and CaMKII: requirement for GluR1 and PDZ domain interaction. Science 287: 2262-2267.

Hirsch LJ, Weintraub D, Du Y, Buchsbaum R, Spencer HT, Hager $M$ et al (2004). Correlating lamotrigine serum concentrations with tolerability in patients with epilepsy. Neurology 63: 1022-1026.

Kaddis FG, Uretsky NJ, Wallace LJ (1995). DNQX in the nucleus accumbens inhibits cocaine-induced conditioned place preference. Brain Res 697: 76-82.

Kendell SF, Krystal JH, Sanacora G (2005). GABA and glutamate systems as therapeutic targets in depression and mood disorders. Expert Opin Ther Targets 9: 153-168.

Knapp RJ, Goldenberg R, Shuck C, Cecil A, Watkins J, Miller C et al (2002). Antidepressant activity of memory-enhancing drugs in the reduction of submissive behavior model. Eur J Pharmacol 440: 27-35.

Krystal JH, Sanacora G, Blumberg H, Anand A, Charney DS, Marek $\mathrm{G}$ et al (2002). Glutamate and GABA systems as targets for novel antidepressant and mood-stabilizing treatments. Mol Psychiatry 7(Suppl 1): S71-S80.

Kwan P, Brodie MJ (2001). Effectiveness of first antiepileptic drug. Epilepsia 42: 1255-1260.

Lee HK, Barbarosie M, Kameyama K, Bear MF, Huganir RL (2000). Regulation of distinct AMPA receptor phosphorylation sites during bidirectional synaptic plasticity. Nature 405: 955-959.

Lee HK, Kameyama K, Huganir RL, Bear MF (1998). NMDA induces long-term synaptic depression and dephosphorylation of the GluR1 subunit of AMPA receptors in hippocampus. Neuron 21: 1151-1162.

Lees G, Leach MJ (1993). Studies on the mechanism of action of the novel anticonvulsant lamotrigine (Lamictal) using primary neurological cultures from rat cortex. Brain Res 612: 190-199.

Li X, Tizzano JP, Griffey K, Clay M, Lindstrom T, Skolnick P (2001). Antidepressant-like actions of an AMPA receptor potentiator (LY392098). Neuropharmacology 40: 1028-1033.

Li Y, Vartanian AJ, White FJ, Xue CJ, Wolf ME (1997). Effects of the AMPA receptor antagonist NBQX on the development and expression of behavioral sensitization to cocaine and amphetamine. Psychopharmacology (Berlin) 134: 266-276.

Malenka RC (2003). Synaptic plasticity and AMPA receptor trafficking. Ann NY Acad Sci 1003: 1-11.

Malinow R, Malenka RC (2002). AMPA receptor trafficking and synaptic plasticity. Annu Rev Neurosci 25: 103-126.

Mammen AL, Kameyama K, Roche KW, Huganir RL (1997). Phosphorylation of the alpha-amino-3-hydroxy-5-methylisoxazole4-propionic acid receptor GluR1 subunit by calcium/ calmodulin-dependent kinase II. J Biol Chem 272: 32528-32533.

Manji HK, Lenox RH (2000). Signaling: cellular insights into the pathophysiology of bipolar disorder. Biol Psychiatry 48: $518-530$

Ossowska K, Pietraszek M, Wardas J, Wolfarth S (2004). Potential antipsychotic and extrapyramidal effects of $(R, S)$-3,4-dicarboxyphenylglycine $[(R, S)-3,4-D C P G]$, a mixed AMPA antagonist/ mGluR8 agonist. Pol J Pharmacol 56: 295-304. 
Roche KW, O’Brien RJ, Mammen AL, Bernhardt J, Huganir RL (1996). Characterization of multiple phosphorylation sites on the AMPA receptor GluR1 subunit. Neuron 16: 11791188.

Rogawski MA, Loscher W (2004). The neurobiology of antiepileptic drugs for the treatment of nonepileptic conditions. Nat Med 10: $685-692$.

Rumpel S, LeDoux J, Zador A, Malinow R (2005). Postsynaptic receptor trafficking underlying a form of associative learning. Science 308: 83-88.

Shao L, Young LT, Wang JF (2005). Chronic treatment with mood stabilizers lithium and valproate prevents excitotoxicity by inhibiting oxidative stress in rat cerebral cortical cells. Biol Psychiatry 58: 879-884.

Smith KE, Gibson ES, Dell'Acqua ML (2006). cAMP-dependent protein kinase postsynaptic localization regulated by NMDA receptor activation through translocation of an A-kinase anchoring protein scaffold protein. J Neurosci 26: 23912402.

Sun X, Zhao Y, Wolf ME (2005). Dopamine receptor stimulation modulates AMPA receptor synaptic insertion in prefrontal cortex neurons. J Neurosci 25: 7341-7351.
Svenningsson P, Tzavara ET, Witkin JM, Fienberg AA, Nomikos GG, Greengard P (2002). Involvement of striatal and extrastriatal DARPP-32 in biochemical and behavioral effects of fluoxetine (Prozac). Proc Natl Acad Sci USA 99: 3182-3187.

Szymczyk G, Zebrowska-Lupina I (2000). Influence of antiepileptics on efficacy of antidepressant drugs in forced swimming test. Pol J Pharmacol 52: 337-344.

Vanover KE (1998). Effects of AMPA receptor antagonists on dopamine-mediated behaviors in mice. Psychopharmacology (Berlin) 136: 123-131.

Wolf ME, Sun X, Mangiavacchi S, Chao SZ (2004). Psychomotor stimulants and neuronal plasticity. Neuropharmacology 47: 61-79.

Zarate Jr CA, Payne JL, Quiroz J, Sporn J, Denicoff KK, Luckenbaugh D et al (2004). An open-label trial of riluzole in patients with treatment-resistant major depression. $\mathrm{Am}$ J Psychiatry 161: 171-174.

Zarate Jr CA, Quiroz JA, Singh JB, Denicoff KD, De Jesus G, Luckenbaugh DA et al (2005). An open-label trial of the glutamate-modulating agent riluzole in combination with lithium for the treatment of bipolar depression. Biol Psychiatry 57: $430-432$.

Supplementary Information accompanies the paper on the Neuropsychopharmacology website (http://www.nature.com/ npp) 